\title{
Análisis de las ideologías desde el modelo de la complejidad
}

\section{Analysis of ideologies from the complexity model}

\author{
José Luis Sardón Martín, Ph. Dr. \\ IES Alonso de Madrigal \\ Ávila (España) \\ sarmarjo@hotmail.com
}

\begin{abstract}
Resumen - El presente trabajo pretende contextualizar el modelo de la complejidad como alternativa al pensamiento fuerte, reduccionista, formalizado y formalizador que ha practicado la humanidad durante siglos y que aún permanece vigente, enemigo de la pluralidad, del perspectivismo. Pretende, también, mostrar diferentes ámbitos, aparentemente dispersos, en los que se manifiesta la complejidad.
\end{abstract}

Palabras clave- ideología, sectarismo, sistema, paradigma, complejidad, diversidad, organización, hermenéutica, historicismo, niihilismo, pensamiento débil.

Abstract - This work tey to contextualise the paradigm of complexity as an alternative to strong, reductionist, formalizing and formalized thought, which humanity has practised for centuries and still remains in force, enemy of plurality and perspectivism. It also intends to show different areas, apparently diverse, in which complexity manifests itself.

Key Words- ideology, sectarianism, system, complexity, diversity, organization, hermeneutics, historicism, nihilism, weak thinking

\section{1.- Una aproximación a las ideologías}

Todos hemos sido educados en un sistema de valores. Hemos sido socializados desde nuestra infancia y seguimos estando socializados hasta el final de nuestras vidas. Imposible no tener ideas en nuestras cabezas. Imposible no tener una "visión de la realidad" que se nos ha inculcado desde nuestra niñez, en el ámbito familiar, escolar, social.

Hay diferentes formas de "amueblar" las cabezas de las gentes. En el modelo tradicional familiar todo gira en torno a la figura del padre (patriarcado) o de la madre (matriarcado), quienes deciden sobre lo que se debe pensar, hacer, decir, sentir, creer. Respeto y continuidad a la tradición. Es en este ámbito familiar donde se fragua el plano de nuestras mentes, de nuestras aptitudes, encaminadas fundamentalmente a la aceptación social. Subyace a esta actitud la moral del rebaño, el sentido de pertenencia a una "comunidad fingida" pues, como decía Kant, no hay que perder de vista la insociable sociabilidad humana.

Hoy, en plena era digital, las cosas son similares en muchos sentidos. El patriarcado/matriarcado lo ejerce la globalización. El rebaño se relaciona a través de dispositivos electrónicos. Su radio de acción se ha extendido. Se mantiene la necesidad de pertenencia a "la comunidad". La necesidad de no sentirse excluido. Moral de rebaño digital y consumista.

Las actitudes sectarias han sido una constante en la historia de la humanidad. Unas veces, debido a la ignorancia y al poder de la persuasión. Otras veces, a intereses meramente personales. El diccionario de la RAE define sectarismo del siguiente modo: 
«Cualidad o actitud propia de la persona que defiende y sigue con fanatismo e intransigencia una idea o una doctrina, sin admitir ninguna crítica sobre la misma».

Tras las ideologías subyace este propósito. Las sectas persuaden a las personas y las utilizan en pro de sus intereses. Marx diría que las alienan. Muchas veces, las sectas actúan intencionadamente en silencio, de manera discreta para pasar desapercibidas. Últimamente, algunas lo hacen de manera directa y ostentosa, haciendo notar su presencia. Es el caso de la emergencia de partidos políticos de la extrema derecha en muchos países. Practican la dualidad buenos-malos, patriotas-antipatriotas y decoran sus actos públicos y privados con banderas y símbolos de todas las clases para fijar en mentes ignorantes y dóciles un elemento de identidad y de pertenencia. Muchas personas se aferran a ellas como si fuesen un salvavidas.

El cebo es cualquier elemento que sea capaz de captar con su canto de sirena a gentes para esclavizarlas, siempre en favor de intereses personales de cualquier índole. Gente necesitada de pertenecer a una "comunidad" por carecer de criterio propio. Gente en situación de minoría de edad, como diría Kant, que no se atreven a dar el paso a la mayoría de edad. Y gentes así nunca faltan. Algunas de ellas pertenecen a las masas. Otras, a las élites.

E. Durkheim definió los hechos sociales como modos de actuar, pensar y sentir externos al individuo que poseen un poder de coerción en virtud del cual se imponen a él. Es decir, socializarse no es otra cosa que interiorizar modos colectivos de pensar, de sentir y de obrar que el contexto familiar, social y escolar nos imponen.

Políticos, líderes, demagogos, multinacionales, han sabido sacar partido a ello. Han encontrado estrategias para lograr sus oscuros propósitos. Aprovechándose de la minoría de edad de gran parte de la población. De individuos que no saben o no quieren tomar sus propias decisiones, de individuos que prefieren dejarse arrastrar por la inercia, de individuos pasivos, acríticos, impersonales, anónimos. Partidarios, también, del clientelismo político y social.

\section{2.- Críticas a las ideologías}

Historicismos, filosofías de la historia, relatos y metarrelatos. Profecías históricas que han sido utilizadas para justificar, con falsos argumentos, acciones de dominación y crueldades inimaginables.

Una de las críticas más conocidas es la que formularon Marx y Engels. Juzgaron que la superestructura, que contiene los conocimientos, los valores, las normas y, en definitiva, la cosmovisión de una época histórica, depende de una base material, de unas determinadas condiciones materiales de vida (infraestructura). En su crítica al idealismo, Marx y Engels (1970) [15] han insistido en que «no es la conciencia la que determina la vida, sino la vida la que determina la conciencia» (p. 26). El marxismo surgió como crítica a la concepción hegeliana del hombre y de la historia; pretendía asestar un duro golpe a las pretensiones del idealismo y a la construcción de grandes sistemas. El materialismo, tanto el histórico como el dialéctico, se han ocupado del cambio; pero, en ellos, existe una extraña alianza entre la libertad y la necesidad porque, en última instancia, los cambios se rigen por leyes necesarias, rígidas, independientes de la voluntad humana.
Marx propuso una reificación (Verdinglichung) del hombre, pues, en el caso de que tenga sentido hablar de la "naturaleza humana", en ningún caso se trataría de una naturaleza abstracta, conceptual, idealizada, estática, acabada. Al contrario, Marx y Engels (1970) consideraron que «lo que los individuos son depende de las condiciones materiales de su producción» (p. 20). El individuo no posee esencia inmutable alguna que le venga dada de antemano; su ser es resultado de una producción, resultado de su historicidad, de su praxis social.

Las ideologías, para Marx, son relatos que pretenden deformar la realidad para que los individuos no sean conscientes de las alienaciones que sufren. Las alienaciones son de índole económica, religiosa, político-social... En $L a$ miseria de la filosofía denuncia a quienes la han utilizado para justificar un orden establecido. La misión del filósofo, sostienen Marx y Engels (1970), no debe ser ésta, sino mostrar la necesidad del cambio, de la transformación. Debe ser una filosofía de la praxis:

«Los filósofos se han limitado a "interpretar" el mundo de distintos modos; de lo que se trata es de transformarlo». (p. 668).

Pero, en realidad, el materialismo histórico constituye otro relato, pretende ser una visión omnicomprensiva de la historia humana, mostrar el discurrir necesario de la misma y su finalidad.

De ahí las críticas que algunos, como K.R. Popper han vertido sobre la supuesta "ciencia de la historia", sobre los historicismos. Popper (1973) [26] otorga este adjetivo a todas aquellas doctrinas que «mantienen un punto de vista sobre las ciencias sociales que suponen que la predicción histórica es el fin principal de éstas, y que suponen que este fin es alcanzable por el descubrimiento de los "ritmos" o los "modelos", de las "leyes" o las "tendencias" que yacen bajo la evolución de la historia» (p. 17).

Semejantes doctrinas son (incluido el marxismo), a juicio de Popper, quien sufrió en sus propias carnes las secuelas del nacismo, tan convincentes como engañosas, y pretende refutarlas argumentando del siguiente modo: la evolución de la historia humana está en gran medida determinada por el incremento de nuestros conocimientos; los métodos racionales o científicos no tienen capacidad para predecir el futuro crecimiento de los conocimientos humanos; por tanto, no resulta posible predecir el desarrollo futuro de la historia humana.

Una "ciencia" de la historia y de la sociedad semejantes a la física teórica son, según Popper, un imposible y, en consecuencia, cualquier predicción histórica carece científicamente de fundamentos. No obstante, este autor hace algunas matizaciones a su argumento. En primer lugar, éste no refuta la posibilidad de predicción, pero sí la predicción de sucesos históricos en tanto que puedan estar influidos por el crecimiento de nuestros conocimientos. En segundo lugar, declara que el fatalismo y la pasividad no son, sin embargo, actitudes típicas de la mentalidad historicista, en clara alusión a la tesis XI de las Tesis sobre Feuerbach de K. Marx.

La concepción marxista de la historia es ajena a cualquier tipo de humanismo tradicional; al contrario, el verdadero 
conocimiento del hombre surge de la crítica y de la oposición a la misma (Althusser, 1968) [1].

Esta crítica se puede aplicar también a Popper. En efecto, su posicionamiento no parece coherente con su oposición a los historicismos. Su defensa de la libertad y del indeterminismo es más impulsiva que racional. En su autobiografía reconoce haber sido comunista en su juventud. Pero hace referencia a un acontecimiento que le condujo a modificar radicalmente sus creencias declarándose desde ese momento enemigo acérrimo del marxismo (Popper, 1977, 1957) [25], [27]. ¿Fue consciente que, de este modo, se erigió en enemigo de todos aquellos que creen en la posibilidad de cambiar para mejorar la sociedad en la que viven haciendo uso de su libertad?.

El crítico más feroz y radical de todos los relatos que sustentan la cultura occidental fue, sin duda, Nietzsche. Este filólogo, que pronto se apasionó por la filosofía, pretendió mostrar las consecuencias que, inherentes a la misma tradición, habían llevado al hombre a un estado lamentable. Profundo conocedor de la antigua Grecia, convirtió a Sócrates y a Platón en el blanco predilecto de sus furibundas críticas. Les acusó de ser los responsables de una inversión de los valores que impone/opone la razón a la vida, lo inteligible a lo irracional, la "virtud" a los instintos, el más allá salvífico al más acá sensible y material, el alma al cuerpo, la permanencia al devenir, la obediencia a la libertad, el esse al possum... Aquellos habrían traicionado el genuino espíritu dionisíaco al declarar a Apolo el único Dios. La tradición judeo-cristiana, por su parte, instauró una moral de esclavos que condenó la vida desde la quimérica ilusión de ofrecer una "fundamentación" a la moral.

En la obra de Nietzsche ya están presentes, a mi entender, muchos de los grandes temas de la postmodernidad y de la hermenéutica. En Crepúsculo de los ídolos condensó en cuatro tesis su crítica a la ontología platónico-cristiana (Nietzsche, 1984, § 6) [22]. Una ontología dualista constituida a partir de la creencia en el engaño de los sentidos, a lo que Nietzsche (1984) [22] responde diciendo que «los sentidos no mienten ni del modo como creen los eléatas ni del modo como creía él [Heráclito], -no mienten de ninguna manera. Lo que nosotros hacemos de su testimonio, eso es lo que introduce la mentira» (\$2). Consecuencia inmediata de esta ontología es la negación de la vida, de la historia, del devenir:

«¿Me pregunta usted qué cosas son idiosincrasia entre los filósofos?... Por ejemplo, su falta de sentido histórico, su odio a la noción misma de devenir, su egepticismo. Ellos creen otorgar un honor a una cosa cuando la deshistorizan, sub specie aeterni, cuando hacen de ella una momia. Todo lo que los filósofos han venido manejando desde milenios fueron momias conceptuales; de sus manos no salió vivo nada real» $(\S 1)$.

Pero contra esta actitud nos previene Zarathustra (1990) [23]:

«¡Permaneced fieles a la tierra, hermanos míos con el poder de vuestra virtud!. ¡Vuestro amor que hace regalos y vuestro conocimiento sirvan al sentido de la tierra!. Esto os lo ruego y a ello os conjuro» (p. 121).
La moral judeo-cristiana es una moral de esclavos (Nietzsche, 1986) [24], pues según Nietzsche, (1985) [20] «lo esencial "en el cielo y en la tierra” es, según parece, repitámoslo, el obedecer durante mucho tiempo y en una única dirección. Con esto se obtiene y se ha obtenido siempre, a la larga, algo por lo cual merece la pena vivir en la tierra [....] Esta tiranía, esta arbitrariedad, esta rigurosa y grandiosa estupidez son las que han educado el espiritu; al parecer, es la esclavitud entendida en sentido bastante grosero y asi mismo en sentido bastante sutil, el medio indispensable también de la disciplina y la selección espirituales: examinese toda moral en este aspecto: la "naturaleza" que hay en ella es la que enseña a odiar el laisser aller, la libertad excesiva, y la que implanta la necesidad de horizontes limitados, de tareas próximas, la que enseña el estrechamiento de la perspectiva y por tanto, en cierto sentido, la estupidez como condición de vida y de crecimiento...» (\$188).

La "muerte de Dios" es la muerte de todos aquellos valores y "verdades" que tenían en él su fundamento. Al ceder la piedra angular de la tradición occidental cae con ella toda una forma de interpretar al hombre y su existencia terrena. De poseer certezas absolutas se ha pasado a la incertidumbre amarga pero esperanzadora. A esta situación se denomina nihilismo. No es un hecho consumado, sino el futuro inmediato de la humanidad. Sin embargo, dice Nietzsche (1970) [21] «esta historia puede ser contada ya ahora, pues opera en ella la necesidad misma. Este futuro habla ya a través de cien signos; este destino se anuncia por doquier; ya todos los oídos están aguzados, prontos a captar esta música del porvenir. Desde hace mucho, toda nuestra cultura europea, presa de una tensión angustiosa que aumenta de década en década, se encamina a una catástrofe...» (La voluntad de poder, § 1).

El nihilismo es pasivo en cuanto que supone decadencia y merma del espíritu. Pero es también activo porque enseña al espíritu que la destrucción del pasado es algo inevitable y necesaria para la construcción del futuro, para la aceptación plena de la vida, para la "realización" del hombre (Nietzsche, 1970, § 25-28). Pero sólo unos pocos están capacitados para captar en profundidad la enorme transcendencia que tiene la muerte de Dios y las consecuencias que arrastra el nihilismo. La nueva tarea, pues, deberá realizarla un hombre nuevo, al que Nietzsche (1985) [20] denomina Übermensch:

«¿A dónde tendremos que acudir nosotros con nuestras esperanzas?. A nuevos filósofos, no queda otra elección; a espíritus suficientemente fuertes y originarios como para empujar hacia valoraciones contrapuestas y para transvalorar, para invertir "valores eternos"; a precursores, a hombres del futuro, que aten en el presente la coacción y el nudo, que coaccionen a la voluntad de milenios a seguir nuevas vías. Para enseñar al hombre que el futuro del hombre es voluntad suya, que depende de una voluntad humana, y para preparar grandes riesgos y ensayos globales de disciplina $y$ selección destinados a acabar con aquel horrible dominio del absurdo y del azar que hasta ahora se ha llamado "historia"» (§ 203).

Sólo este tipo de hombre puede percibir la coyuntura y comprender la necesidad de buscar otros horizontes, otras 
perspectivas. ¿Cuál fue el gran error de la filosofía tradicional?. No haberse percatado de que la lógica y las categorías de la razón sólo son medios de acondicionar el mundo para fines prácticos y creer, por el contrario, que constituyen el criterio de verdad y de realidad (Nietzsche, 1970, § 328) [21]. Dice Nietzsche (1970) [21] que el hombre del futuro, en cambio, sabe que «el valor del mundo está en nuestra interpretación [...] Que las interpretaciones hasta ahora habidas son valoraciones perspectivicas por virtud de las cuales nos afirmamos en la vida, es decir, en la voluntad de poder, de aumento de poder; que toda elevación del hombre comporta la superación de interpretaciones más estrechas; que toda potenciación, todo aumento de poder obra nuevas perspectivas y lleva a creer en nuevos horizontes [...] El mundo que nos atañe es falso, no es realidad, sino invención y elaboración a base de una modesta suma de observaciones; "fluye", en cuanto algo que deviene, una falsedad siempre cambiante que no se aproxima jamás a la verdad; pues no hay ninguna "verdad”》 (§ 326).

Frente al esse, el ser acabado, cerrado y pleno de la tradición, Nietzsche opone el possum, la posibilidad latente de que el hombre pueda ser lo que aún no es, sabiendo que jamás podrá llegar a "ser" en plenitud, de modo definitivo. El futuro es un reto, un puente que debemos ir construyendo a medida que avanzamos por y desde él. Nunca terminaremos su construcción, porque ya no es posible hablar de "metas" de "fines", de "verdades", de "certezas"... Los resentidos, los esclavos, fallecerán por el camino o se lanzarán al vacío por sus flancos; aquellos que aceptan la vida, los que tienen voluntad de poder, continuarán adelante. $\mathrm{Ni}$ el "por qué" ni el "para qué" podrán ya angustiarlos ni obstaculizar su tarea. No podemos volver atrás porque a nuestras espaldas el puente se derrumba; tampoco saltar sobre el vacío que hay delante de nosotros, porque más allá de nuestras narices aún no hay nada. El vértigo y la incertidumbre nos rodean por todas partes. Es preciso tener valor, mucho valor, y por este motivo el futuro sólo puede ser de los fuertes, de los poderosos... (Sardón, 1997) [32].

De quienes tienen la mente abierta, de quienes contemplan diversas perspectivas, de quienes saben interrelacionar, interactuar, complejizar y sistematizar. No de aquellos que ponen etiquetas, de los monotonoteístas, simplificadores, reduccionistas, simplistas.

Dirijámonos ahora a la ontología hermenéutica. Durante siglos, la humanidad ha vivido de fundamentos; pero hoy, como Vattimo ha dicho, "ya no hay fundamento para seguir creyendo en el fundamento". La actual reflexión sobre el hombre no puede erigirse en ninguna antropología como ciencia cerrada; debe ser interdisciplinar; tampoco nos va a ofrecer soluciones ni a proponer ideales de humanidad; tan sólo, aproximarnos a la realidad, analizarla y, de algún modo, buscar vías hacia el futuro.

Tras contemplar con justificada preocupación la tendencia de la hermenéutica a convertirse en una nueva koiné, va a tratar de precisar su sentido y alcance. Vattimo (1995) [35] se desmarca de otros planteamientos para mostrar la vocación nihilista que, a su entender, tiene la hermenéutica, lo que le lleva a considerarla como una ontología:

«No parece posible "probar" la verdad de la hermenéutica si no es presentándola como respuesta a una historia del ser interpretada como acontecer del nihilismo» (p. 45).

«El sentido de la historia de la modernidad, o de la época del ser al que la hermenéutica ha de corresponder, no parece que pueda definirse de otra manera sino como nihilismo» (p. 82).

«Principalmente, este es el sentido "nihilista" de la hermenéutica: si no pensamos que la transición de la metafísica de la presencia a la ontología de la proveniencia es la corrección de un error, sino el acaecer del ser mismo, indicación de su "destino", entonces la tendencia al debilitamiento-ciertamente, sólo en relación con la categoría metafísica de la presencia, de la plenitud- que este curso manifiesta es la verdad del nihilismo de Nietzsche, el sentido mismo de la muerte de Dios, es decir, de la disolución de la verdad como evidencia perentoria y "objetiva"; hasta el momento los filósofos han creído describir el mundo, ahora es el momento de interpretarlo...» (p. 52).

Vattimo critica la metafísica de la presencia en la que la verdad aparece como apropiación y se acoge a una ontología de la proveniencia. De este modo, el italiano se sitúa en la senda que inauguraron Nietzsche con la muerte de Dios y Heidegger con el "después de" o etapa postmetafísica. El primero concede a la hermenéutica vocación nihilista; el segundo, la convierte en una ontología.

La ontología hermenéutica de Vattimo (1995) [36] se estructura en torno a una idea rectora: la actitud antifundamentadora que supone el nihilismo conlleva una concepción debilitada del ser y un pensamiento débil que se orienta hacia las diferencias y rehuye la unidad y la identidad:

«Pensamiento fuerte es aquel que se construye en torno al fundacionalismo, que entiende el ser como plenitud ahistórica y atemporal, que pretende eternizar $\mathrm{y}$ eternizarse. El pensamiento débil, sin embargo, se nutre de la pluralidad, del relativismo, de la perspectiva, de la interpretación. También existiría un pensamiento trágico propio de resentidos, que surge al observar con melancolía y desesperación el desvanecimiento, la agonía de sus eternas verdades. Tanto el fuerte como el trágico son formas de pensamiento muertas. El primero sólo aspira a perpetuarse, a imponerse, a monopolizar. El segundo, a lamentarse y oponer una ya inútil resistencia a su inevitable ocaso. En el fondo, se trata de una misma forma de pensar, una de ellas propia de épocas de esplendor y de optimismo; la otra, de momentos en los que la crisis se intuye como imparable e irreversible. El pensamiento débil no es ni debe ser trágico porque no se aferra al dogmatismo como una lapa, porque no tiene dependencia absoluta ni en relación a los fundamentos ni en relación al tiempo. De este modo, es más libre para crear y recrear y se considera a sí mismo hijo del tiempo y de la historia. No vive las crisis con dramatismo sino que las admite como una chance y es consciente de que, sólo así, es posible seguir caminando hacia adelante» (p. 30).

Heidegger recurrió al término Verwindung para señalar la necesidad de deshacernos de toda la ideología que dominó la modernidad como único modo de recuperarnos de esa 
enfermedad. Pero no sustituyéndola por otra, pues entonces estaríamos cayendo en la misma trampa.

Los nuevos enfoques humanistas rechazan también aquellos relatos que presentan la historia como un proceso lineal y como unidad global de sentido, aquellas filosofías de la historia de talante historicista que enmascaran la temporalidad y que presuponen y explicitan una concepción esencialista y cerrada de la naturaleza humana, que limitan las posibilidades de realización de lo humano entre las que se incluyen, fundamentalmente, la teología judeocristiana de la historia, el historicismo ilustrado, la filosofía de la historia de Hegel e incluso, como más arriba he explicado, el propio marxismo.

Durante siglos, la historia concedió sentido a la existencia humana, tanto si se entiende como tradición determinada y determinante (es decir, como unidad estable de sentido), cuanto si se entiende como progreso y superación constantes. Pero hoy la historia, dice Vattimo (1997) [37], ya no puede ser comprendida de ninguna de estas dos formas:

«...debe reconocerse que lo posmoderno se caracteriza no sólo como novedad respecto a lo moderno, sino también como disolución de la categoría de lo nuevo, como experiencia del "fin de la historia", en lugar de presentarse como un estadio diferente (más avanzado o más retrasado; no importa) de la historia misma» ( $p$. 12).

«Pero si no hay una historia unitaria, portadora de la esencia humana y si sólo existen diversas historias, los diversos niveles y modos de reconstrucción del pasado en la conciencia y en la imaginación colectiva, es difícil ver hasta qué punto la disolución de la historia como diseminación de las "historias" no es también propiamente un verdadero fin de la historia como tal, de la historiografía como imagen, por más abigarrada que sea de un curso unitario de acontecimientos, el cual también (una vez eliminada la unidad del discurso que hablaba él) pierde toda consistencia reconocible» ( $p$. 16).

No debe quedar duda alguna, pues, sobre el giro que Vattimo (1997) da a esta cuestión:

«Uno vuelve a apropiarse del sentido de la historia con la condición de aceptar que ésta no tiene un sentido de peso ni una perentoriedad metafísica y teológica» (p. 31).

Vattimo se ha mostrado crítico ante el proyecto ilustrado de conformar un mundo cosmopolita regido por unos mismos principios universales $\mathrm{y}$, en consecuencia, declaran que ya no es posible seguir manteniendo una visión unitaria de la historia, una historia concebida como unidad compacta de sentido. En este contexto en el que la historia ya no debe ser entendida como progreso y superación constantes, la deuda con algunos antropólogos socioculturales es también palpable.

Este etnocentrismo, esta occidentalización de la cultura, de la economía, de la política y de todo lo demás se muestra intolerante ante el derecho de cualquier pueblo y cultura a optar por formas de desarrollo propias. W. Benjamin, W. James y otros se han opuesto a la homogeneidad cultural, a la imposición universal del modelo europeo-occidental- racionalista-ilustrado como único modelo posible de progreso, pues, en el fondo, se trataría de un fundamentalismo y de una ideología más. Es preciso abandonar el enfoque diacrónico del historicismo que esclaviza al hombre y a la cultura y adoptar una perspectiva sincrónica que contemple la variedad y la espontaneidad de las experiencias culturales, de la verdad, de la realidad. Sólo de este modo la democracia dejará de ser un relato ideológico al servicio de las clases dominantes y podrá convertirse en un hecho, en una posibilidad real, en verdadero respeto a la diversidad y la pluralidad. Por supuesto, el relativismo cultural y el derecho que asiste a cada pueblo a hacer y tener su propia historia no debe ser utilizado para la práctica de conductas que atentan contra los derechos humanos más fundamentales, como ciertos rituales, pero Occidente tampoco tiene autoridad moral para, aprovechándose de ello, aniquilar por completo a cualquier competidor (Gómez, 2000; Marina y Válgoma, 2001; García Valdés , 2000) [8], [14], [5].

Vattimo (1997) [37], por su parte, ha dicho lo siguiente:

«[En la postmodernidad] no todo se acepta como camino de promoción de lo humano, sino que la capacidad de discernir y elegir entre las posibilidades que la condición posmoderna nos ofrece se constituye únicamente sobre la base de un análisis de la posmodernidad que la tome en sus caracteres propios, que la reconozca como campo de posibilidades y no la conciba sólo como el infierno de la negación de lo humano» (p. 19)

Está convencido, pues, de que el nihilismo no propugna una deshumanización, sino que provoca posibles y plurales experiencias humanas nuevas, idea que yo comparto (1997) [32] totalmente con él:

«Cuando el mar está tranquilo y el viento es débil no dudamos en aventurarnos mar adentro en una ligera y frágil balsa, pues de surgir problemas siempre habrá algún mercante, un pesquero o una patrullera que nos ayude. Pero cuando el océano ruge embravecido y amenazador debemos ser más cautelosos porque, si tenemos problemas, es probable que nadie acuda en nuestra ayuda, que cualquier navío con bandera falsa o el irresistible canto de las sirenas nos conduzcan al reino del idealismo y del dogmatismo. Hoy el mar ruge furioso ante nuestra isla desprovista de provisiones y ya no es posible demorar más la partida. Nuestra nave debe ser fuerte y es preciso calcular bien la fuerza del viento y la intensidad de las corrientes. No conviene construirla demasiado pesada porque el lastre podría llevarnos a pique en la primera ola; ni demasiado ligera para no ser arrastrados a la deriva. Antes de partir debemos estar seguros de que el capitán, el timonel y los demás miembros de la tripulación forman equipo sólido y competente, pues prevemos que la travesía será larga, dura y azarosa. Cada día deberemos aprender a sobrevivir a las inclemencias atmosféricas que, sin duda, se producirán. $\mathrm{Ni}$ la luz del sol debe deslumbrarnos, ni el abismo que se abre a nuestros pies debe amedrentarnos. En mucho tiempo no divisaremos un faro salvador ni tierra firme donde reponer fuerzas. Pero cada jornada transcurrida habremos recorrido un trecho y tendremos en común algo más de lo que 
compartíamos antes de zarpar, a pesar de las discrepancias y de las dudas que surgirán entre nosotros. Poco a poco aprenderemos que es importante reflexionar y tener las ideas claras, pues no estamos embarcados en un crucero de placer. Después de cubrir una etapa deberemos preparar la siguiente, y así sucesivamente. La curiosidad, las dificultades y el afán de superación han forjado los grandes espíritus que han impulsado a la humanidad. La pequeña isla fue durante un tiempo nuestro hogar; en ella vivimos felices un tiempo que sabíamos no iba a durar eternamente, pues antes o después se nos quedaría pequeña. La recordamos con cariño y jamás se nos pasó por la cabeza destruirla o borrarla de nuestros mapas, pues quizás fuese preciso regresar a ella y planear de nuevo el viaje. Algunos no quisieron o no tuvieron el valor necesario para abandonarla. Los unos y los otros pensamos de vez en cuando en voz baja: “¡Qué habrá sido de ellos!"’».

Ni el hombre es una entidad cerrada y acabada (un plenum), ni su futuro está escrito de antemano en parte alguna. Las condiciones van generando las leyes; me niego a admitir que sean unas supuestas leyes eternas las que generen siempre y del mismo modo idénticas condiciones. Las profecías históricas son aplastadas por el peso de la realidad. El futuro es algo que se construye desde el presente, y las circunstancias vitales raras veces permiten avanzar en línea recta. En todo momento tenemos necesidad de ensayar nuevas formas de vida. No tenemos otra alternativa que crear y recrear ininterrumpidamente nuestra existencia. Una vez que el fundamento y la certeza quedaron atrás, nuestros únicos recursos son la voluntad, la inteligencia y la imaginación. Nos movemos en el territorio de la provisionalidad y de la previsión a corto plazo. Es así como ha transcurrido durante miles de millones de años la historia de la vida en la Tierra. Nosotros, jamás debemos olvidarlo, somos seres vivos y naturales.

\section{3.- El paradigma de la complejidad}

El paradigma clásico era fundacionalista, pues creía que todo tiene un fundamento $\mathrm{y}$ que es preciso hallarlo $\mathrm{y}$ divulgarlo a los cuatro vientos. Pero no sirve cualquier fundamento, no. Éste, tiene que ser lo más absoluto e inmutable posible.

En el ámbito de la ciencia, el esfuerzo se orientó al descubrimiento de las leyes inmutables que rigen los fenómenos físicos. El azar, la sorpresa, no tienen cabida en este paradigma. El mecanicismo y el determinismo, apoyándose en un aparato matemático preciso, creen poder predecir con total seguridad cuantos acontecimientos sucedan en el universo. En este clima de optimismo, el control de la teoría y de la realidad se convirtieron en objetivos fundamentales (Sardón, 1990) [33]. Pero hoy, como remarcan Prigogine y Stengers (1983) [29], sabemos que «la ciencia es como un juego entre dos participantes en donde tenemos que adivinar el comportamiento de una realidad sin relación con nuestras creencias, nuestras ambiciones o nuestras esperanzas. No puede forzarse a la naturaleza a decir lo que queramos. La investigación científica no es un monólogo. Es precisamente el riesgo que comporta lo que hace el juego singular e intensamente emocionante» (p. 16).
Emerge, pues, el paradigma de la complejidad, el pensamiento sistémico y recursivo en el ámbito científico, de lo que Wagensberg (1985) [38] es plenamente consciente:

«Un concepto que la ciencia moderna intenta aprehender sin haber conseguido todavía definir satisfactoriamente es la complejidad. Las preocupaciones fundamentales son dos: el cambio y la relación entre los todos y sus partes. La primera se refiere a la estabilidad y la evolución, la segunda a la estructura y a la función» (p. 9).

Prigogine y Stengers (1983) [29] avalan este planteamiento:

«El interés de la ciencia se está trasladando desde lo simple a lo complejo. La creencia en la simplicidad del mundo microscópico se ha desvanecido. Esta reorientación del interés nos lleva a enfatizar nuevos conceptos y nuevos métodos» (pp. 13-14).

Así pues, desde hace tiempo, en algunas parcelas de la investigación científica se han descubierto fenómenos, procesos, hechos y comportamientos que no encajan en los rígidos esquemas de la ciencia clásica ni pueden ser comprendidos y expresados con sus conceptos, principios y categorías. Con ello se pone de manifiesto lo que desde tiempo atrás se venía anunciado y que, estoy seguro, la mayoría de los hombres de ciencia sabían pero no podían o no se atrevían a aceptar: la realidad es compleja. La ciencia contemporánea ha redescubierto la complejidad de lo real, descubrimiento que no afecta exclusivamente a la realidad física; sus implicaciones epistemológicas, además, son decisivas. Todo ello redunda en un nuevo modo de entender la práctica científica, en una nueva actitud ante la naturaleza, en una nueva concepción del hombre, de la verdad y de la objetividad. Y, también, por supuesto, en una nueva concepción del método. Estos descubrimientos ofrecen evidencias científicas al pensamiento sistémico, cooperativo, sinergético, interdisciplinar, recursivo, abierto, creativo. No queda lugar para el pensamiento único.

La física de partículas ha descubierto, nos dice Treffil (1988) [34], que el mundo subatómico es plural y muy diferente al que vemos a simple vista:

«De algún modo, el mapa de la física es similar al mapa lingüístico de la Tierra. Así como los idiomas que se hablan en distintos lugares de la Tierra son diferentes, también lo son las leyes que gobiernan los distintos aspectos de la Física [...] Una partícula elemental no es una partícula en el sentido en que lo es una bala de revólver, pero tampoco es una onda como las olas del mar. Exhibe propiedades que se asocian normalmente a cada una de estas cosas, pero constituye un tipo de fenómeno completamente nuevo» (pp. 31 y 33).

Heisenberg (1976) [11] afirma que «la noción de realidad objetiva de las partículas elementales se ha disuelto [...] en la transparente claridad de una matemática que describe, no el comportamiento de las partículas elementales, pero sí nuestro conocimiento de dicho comportamiento» (p. 11).

La teoría general de sistemas nos enseña que no existen objetos aislados, sino dentro de entornos, de contextos. 
Según Bertalanffy (1980) [4], el modelo sistémico consiste en «hacer hincapié en la consideración del organismo como un todo o sistema y ver el objetivo principal de las ciencias biológicas en el descubrimiento de los principios de organización en sus diversos niveles» (p. 10).

El éxito del nuevo enfoque sistémico dependía de su capacidad para abordar problemas de complejidad organizada (es decir, problemas de interrelación entre un número finito, pero grande, de componentes o variables); para desarrollar técnicas matemáticas ad hoc; para vencer la oposición de la epistemología tradicional; para acuñar un nuevo repertorio terminológico y categorial. Bertalanffy (1980) concedió a la teoría de sistemas por él formulada carácter universal haciendo extensibles, tanto sus principios como sus conclusiones, a cualquier sistema con independencia de cuál sea su naturaleza:

«Existen modelos, principios y leyes aplicables a sistemas generalizados o a sus subclases, sin importar su particular género, la naturaleza de sus elementos componentes y las relaciones o fuerzas que imperan entre ellos [...] Parece legítimo pedir una teoría no ya de sistemas de clase más o menos especial, sino de principios generales aplicables a los sistemas en general» (p. 32).

«La teoría general de los sistemas ha contribuido a la expansión de la teoría científica, que ha conducido a nuevas visiones $\mathrm{y}$ principios $\mathrm{y}$ ha abierto nuevos el orden universal?, sino que es: ¿por qué hay orden y organización en el cosmos?. Al dejar de constituir evidencias ontológicas, el orden y la organización devienen problemas y misterio: deben ser explicados, justificados, legitimizados» (p. 54).

La termodinámica de los procesos irreversibles muy alejados del equilibrio describe procesos termodinámicos que se producen en sistemas muy alejados del equilibrio y sometidos a condiciones ambientales extremas los cuales sólo han sido objeto de estudio en las últimas décadas (Glansorff y Prigogine, 1971; Nicolis y Prigogine, 1977; Lurié y Wagensberg, 1979; García Velarde, 1978; Prigogine, 1976; Lavenda, 1985; Groot, 1968) [7], [19], [13], [6], [28], [30], [12], [9]. Poco a poco, los científicos fueron descubriendo que, lejos del equilibrio, las cosas suceden de muy distinta manera. En esta región ya no se dispone de un potencial (la producción de entropía) con el que describir y prever la evolución de los sistemas. Una vez superada la linealidad, ciertos sistemas se muestran incapaces de adaptar las fluctuaciones $y$, en consecuencia, de asegurar su estado estacionario. En otras palabras, más allá de la linealidad, la estabilidad ya no es el resultado lógico y previsible de las leyes físicas consideradas como universales. Diferentes experimentos muestran que, lejos del equilibrio, las fluctuaciones que se producen a nivel microscópico pueden ser amplificadas a nivel macroscópico y arrastrar al sistema a nuevos e imprevistos estados estacionario de no equilibrio. De este modo se originan lo que Prigogine y Stengers (1983) [29] ha denominado estructuras disipativas, auténticas y sorprendentes novedades en el modo de organizarse la materia: problemas investigables, es decir, que se prestan a mayor estudio, experimental o matemático. Son obvias las limitaciones de la teoría y de sus aplicaciones en el estado actual, pero los principios parecen ser en lo esencial acertados, según se aprecia por su aplicación a diferentes campos» (p. 123).

Esta teoría en modo alguno pretende simplemente ofrecer soluciones concretas y puntuales sino, sobre todo, abrir nuevas perspectivas en la investigación, en el conocimiento interdisciplinar y en el diálogo desinteresado y objetivo con la realidad. No nos dice cómo es ni cómo debe ser ésta; simplemente, nos ofrece un nuevo modo de acercarnos a ella. Ya no cabe dudar sobre la complejidad de la naturaleza; pero tenemos todavía que desentrañar la naturaleza de la complejidad.

La segunda ley de la Termodinámica dejó en entredicho la existencia de un orden universal inalterable que prohibía cualquier tipo de desorden. Morin (1981) [17] insiste en que desde el orden como "evidencia" nos trasladamos al orden como problema:

«Como en toda restauración, un pilar del orden antiguo se había hundido y la misma idea de orden se había problematizado. A partir del momento en que se plantea que los estados de orden y de organización no sólo son degradables, sino improbables, la evidencia ontológica del orden se encuentra invertida. El problema ya no es: ¿por qué hay desorden en el universo aunque en él reine «En condiciones muy alejadas del equilibrio, los mecanismos selectivos tienen una presión de un orden de magnitud diferente que cerca del equilibrio. Expresándolo en términos algo antropomórficos: muy lejos del equilibrio, la materia empieza a percibir su entorno, a distinguir entre pequeñas diferencias que serían insignificantes en el equilibrio. La razón es bien simple: en el equilibrio o cerca de él, sólo tenemos una estructura que pueda alterarse cuando cambiamos su entorno; las fluctuaciones muy alejadas del equilibrio nos permiten utilizar las diferencias en el entorno para producir estructuras diferentes. Una vez más pongamos énfasis en la singular importancia de las condiciones muy alejadas del equilibrio: comunicación y percepción son las palabras clave en el nuevo comportamiento de la materia muy lejos del equilibrio» (p. 167).

Se conocen diferentes tipos de estructuras disipativas, como la inestabilidad de Bénard, las reacciones químicas oscilantes, el comportamiento del láser según la interpretación realizada por Hans Haken...

La siguiente tabla refleja las diferencias enre ls descripción dinámica y la descripción termodinámica: 
1. Busca la elementalidad y la simetría.

2. Todos los fenómenos son, o serán en el futuro, susceptibles de una explicación dinámica («salvar los fenómenos»).

3. El objetivo y el orgullo de la explicación dinámica es la predicción, para lo que postula una causalismo determinista riguroso.

4. El tiempo es mera ilusión (magnitud, variable matemática), algo externo, y la irreversibilidad subproducto de la subjetividad y de la ignorancia.

La teoría de la información también ha realizado aportaciones al campo de la complejidad. Es preciso distinguir con claridad entre: información libre, en relación a eventualidades abstractas que carecen de significación física precisa (por ejemplo, la que aporta una tirada de dados) e información ligada, que si posee significación. Hace referencia a la información que un observador posee sobre los diferentes microestados en los que puede encontrarse un sistema en momentos distintos. Este tipo de información se utiliza para medir el grado de complejidad, es decir, de organización (Shannon y Wiever, 1949) [31].

El principio de complejidad por el ruido tiene dos orígenes precisos. Uno es la teoría matemática de la información que elaboraron Shannon y Weaver. Otro, procede de los desarrollos e interpretaciones que siguieron a aquélla, sobre todo, el análisis de las relaciones entre la función $H$ de Shannon (cantidad de información) y la función $S$ de Boltzmann (entropía).

El «caos determinista». En el seno de sistemas muy alejados del equilibrio o afectados por factores de "ruido", las perturbaciones pueden producir ciertas formas de orden y de organización cuando, lo más probable teóricamente serían la dispersión y el desorden. Además, y para que nuestra capacidad de sorpresa no cese, en los llamados sistemas dinámicos se producen comportamientos caóticos cuando ¡se trata de sistemas en los que impera el más rígido

determinismo!. En efecto, se denominan sistemas dinámicos a los procesos de evolución temporales en los que el futuro
1. Descubre que en numerosos procesos y fenómenos reales se produce ruptura de simetría y que ningún elemento puede considerarse de forma aislada o independiente.

2. Muestra que no todos los fenómenos y procesos encajan en los límites de la explicación dinámica, siendo preciso suavizar y relativizar el alcance de las supuestas "leyes universales" («salvar la realidad»).

3. El orden por fluctuaciones y las estructuras disipativas muestran la posibilidad real de creatividad en el mundo material, con lo que el universo se torna complejo e imprevisible.

4. El tiempo y la irreversibilidad tienen el rango de realidades, y la dialéctica orden/ desorden/ organización tiene, a este respecto, gran importancia.

depende de manera determinista del pasado. Y Haken y Wunderlin (1990) [10] concluyen del siguiente modo:

«El descubrimiento de comportamientos erráticos en sistemas no sometidos a fuerzas irregulares o aleatorias, sino por el contrario, regidos por leyes estrictamente deterministas, ha significado la emergencia de un nuevo paradigma llamado caos determinista» (p. 1211).

\section{4.- Las aportaciones de Edgar Morin}

Comenzaré, a modo de introducción, con estas palabras de Morin (1988) [18]:

«Se puede comer sin conocer las leyes de la digestión, respirar sin conocer las leyes de la respiración, se puede pensar sin conocer las leyes ni la naturaleza del pensamiento, se puede conocer sin conocer el conocimiento. Pero, mientras que la axfisia y la intoxicación se dejan sentir inmediatamente como tales en la respiración y en la digestión, lo propio del error y de la ilusión es no manifestarse como error o ilusión: ¡"El error sólo consiste en no parecerlo"! (Descartes). Como dijeron Marx y Engels al comienzo de La ideología alemana, los hombres siempre han elaborado falsas concepciones de sí mismos, de lo que hacen, de lo que deben hacer y del mundo en el que viven. Y Marx y Engels hicieron lo mismo.

Cuando el pensamiento descubre el gigantesco problema de los errores e ilusiones que no han dejado (ni dejan) de imponerse como verdades en el curso de la historia humana, cuando descubre correlativamente que lleva en sí mismo el riesgo permanente del error y la ilusión, entonces debe procurar conocerse» (p. 17). 
Edgar Morin es un conocido, brillante y controvertido intelectual francés que ha orientado sus investigaciones y reflexiones hacia una teoría de la organización. Su aportación consiste, fundamentalmente, en proponer una teoría de la organización inspirada en la muy oportuna caracterización que Angyal ha hecho del sistema como «unitas multiplex». El antiquísimo problema de las relaciones entre unidad y diversidad, movimiento y quietud son retomados por él explícitamente.

Partiendo de las denuncias y de las críticas formuladas años atrás (Morin, 1978) [16] sobre las brechas ontológicas y epistemológicas que, según él, caracterizan el paradigma clásico, propone su proyecto antroposociológico con el fin de conseguir un acercamiento entre los diferentes ámbitos de la realidad, hasta ese momento separados y enfrentados, proyecto que se caracteriza por los siguientes rasgos: (a) superar los dogmatismos y reduccionismos, porque ofrecen una imagen parcial y unilateral de la realidad; (b) evitar las concepciones totalizadoras, en tanto que preconcepciones de lo humano, porque son estáticas y atemporales, porque privan al hombre y a la sociedad de sus atributos fundamentales: la incertidumbre, el devenir, el cambio...; (c) en definitiva, elaborar una interpretación de la complejidad, de sus niveles y de las relaciones que existen entre ellos.

Al igual que Bohr, Heisenberg y otros, Morin (1981) [17] subraya el papel que el sujeto, en tanto que observador y conceptuador, tiene en la imagen que formamos de la realidad. No se trata de un observador ideal privilegiado como el que imaginaron Maxwell, Laplace y Gibbs, sino un ser cuyas capacidades cognoscitivas están inmersas en la praxis científica, cultural y social:

«La ciencia clásica se fundó bajo el signo de la objetividad, es decir, de un universo constituido por objetos aislados (en un espacio neutro) sometidos a leyes objetivamente universales. En esta visión, el objeto existe de manera positiva, sin que el observador/conceptuador participe en su construcción con las estructuras de su entendimiento y las categorías de su cultura. Es sustancial, constituido de materia que tiene plenitud ontológica, es autosuficiente en su ser. El objeto es, pues, una entidad cerrada y distinta, que se define aisladamente en su existencia, sus caracteres y sus propiedades, independientemente de su entorno. Se determina tanto mejor su realidad objetiva cuanto más se le aísla experimentalmente. Así, la objetividad del universo de los objetos se sustenta en su doble independencia con respecto del observador humano y del medio natural» (p. 117).

El antiguo paradigma creyó que el universo se compone de objetos aislados sometidos a leyes universales y objetivas entre los que sólo existen relaciones de índole mecanicista. Atribuyó a los objetos dos propiedades fundamentales: la autosuficiencia ontológica y la existencia positiva; es decir, son lo que son con independencia del observador/conceptuador. Así, conocer un objeto equivale a determinar: su posición y cantidad de movimiento, sus propiedades fisico-químicas y las leyes naturales por las que se rige. Esta actitud se debe, entre otros motivos, a la preeminencia que Descartes concedió a lo analítico y al proyecto de matematización de la naturaleza; por estos motivos, se tendió a la búsqueda de lo simple y elemental y se impuso lo formal-cuantitativo a lo físico y cualitativo.

Uno de los primeros pasos que se deben dar es oponer el sistema al objeto. Dada la intrínseca complejidad que poseen los sistemas, Morin (1981) [17] considera que resulta imposible abarcarlos en una definición única. Es preciso proceder mediante aproximaciones sucesivas, una de las cuales sería ésta:

«Todos los objetos clave de la física, de la biología, de la sociología, de la astronomía, átomos, moléculas, organismos, sociedades, astros, galaxias, constituyen sistemas [...] El ser humano forma parte de un sistema social, en el seno de un ecosistema natural, el cual está en el seno de un sistema solar, el cual está en el seno de un sistema galáctico; está compuesto por sistemas celulares, los cuales están compuestos por sistemas moleculares, los cuales están compuestos por sistemas atómicos» (p. 121).

Morin atribuye carácter polisistémico al universo, pues todos los ámbitos de la realidad se componen de sistemas imbricados unos en otros. Desde aquí propone una primera definición de sistema:

«Una interrelación de elementos que constituye una entidad o unidad global» (p. 123).

Organización es la disposición de las partes en y por el todo; sistema, la unidad compleja y organizada que es el todo interrelacionado; interrelación, el modo de unirse los elementos entre sí y con el todo. Debo insistir en la necesidad de considerar el surgimiento de la interrelación, de la organización y del sistema como tres caras o aspectos fenoménicos de un proceso único y simultáneo que se produce, inicialmente, vía interacciones.

Morin se inclina por la definición de sistema como «unitas multiplex» (Angyal, 1941) [2], porque todo sistema es, al mismo tiempo, uno (desde la perspectiva del todo) y heterogéneo (desde la perspectiva de las partes). También recurre a la interpretación organizacional que ha dado Atlan (1979) [3] de lo que sería una paradoja aparente entre "unidad" y "multiplicidad": la organización consistiría en una extraña relación entre el máximo de variedad (multiplex) y el máximo de orden repetitivo o redundancia (unitas).

Frente al análisis, la medida y la substancialización de los objetos Morin nos propone percibir, concebir y pensar de modo organizacional tanto lo que nos rodea como a nosotros mismos.

El todo es más que la suma de las partes, pero también es menos, lo que se debe a la presencia efectiva de los constreñimientos. Éstos pueden ser ejercidos de distintos modos y a diferentes niveles: entre las partes; entre éstas y el todo; entre el todo y aquéllas. Puesto que su misión consiste en mantener la estabilidad de un sistema, los progresos organizacionales sólo serán posibles si el sistema disfruta de algún grado de libertad. Por ejemplo, en las sociedades humanas, la cultura es el factor que permite al espíritu desarrollar sus capacidades; la sociedad, por su parte, exige a los ciudadanos que acaten las reglas del juego y utiliza la censura para reprimir ciertas iniciativas individuales, sobre todo de índole sexual e intelectual. Consecuencia: el precio 
de la estabilidad social es la inhibición de determinadas capacidades individuales; y esto es válido, con matices, para cualquier sistema sociopolítico.

Libertad o ganancias en emergencias y constreñimientos o pérdidas son términos a un mismo tiempo complementarios, recurrentes y antagonistas. Morin no oculta su oposición a las consideraciones meramente cuantitativas de los sistemas, pues lo significativo en ellos no es el número de constituyentes sino sus cualidades emergentes. El sistema es un todo que se constituye de modo paralelo a la transformación de sus elementos. «Todo lo que forma transforma» es, para él, el principio sistémico fundamental. Así, la organización transforma la diversidad en unidad, pero sin eliminar la diversidad, pues ésta genera unidad: por ejemplo, la asociación de partículas y subpartículas heterogéneas que, de algún modo, conservan su individualidad, es lo que concede unidad al átomo. La organización, también, produce diversidad desde, en y por la unidad; es decir, la unidad genera diversidad: por ejemplo, el principio de exclusión de Pauli sostiene que una partícula no puede ocupar, en el edificio atómico, un "estado" (elenco de características que se dan conjuntamente) que ya esté ocupado por otra partícula. En otras palabras, es imposible y absurdo que existan dentro del átomo partículas que posean idénticas características. En el fondo, se trata de un principio de selección y de economía. Se constata, pues, una relación complementaria, concurrente y antagonista entre orden repetitivo y variedad. El predominio del primero acarrea escasez de organización y de emergencias (como sucede en los sistemas cristalinos), y al contrario, cuando la diversidad es predominante, lo más probable es que la organización termine por convertirse en dispersión, pero, ¡no siempre es así!.

Todo sistema se comporta como un par de fuerzas (atracción y exclusión), a un mismo tiempo antagonistas y complementarias. Los antagonismos no tienen por qué ser necesariamente destructores; con frecuencia generan orden y organización.

\section{5.- Conclusiones: en favor de un humanismo más humanizado y humanizador}

Las ideologías pertenecen al pensamiento fuerte. Pero no incitan a pensar. No promueven la crítica, ni la reflexión, ni el análisis. Y no lo hacen porque no se crearon para ello, sino para lo contrario: para persuadir, dominar, influenciar, someter. No promueven el avance del conocimiento, pues sólo hay una verdad que ya la tienen ellas. Y, si es preciso, la imponen a sangre y fuego. En su nombre se han cometido las más aberrantes atrocidades. Y, sin embargo, ahí siguen. Se dejan ver, se dejan notar.

Hoy el mundo entero se ve afectado por una perturbación que ninguna ideología, ningún historicismo, había predicho. Me refiero a la pandemia causada por el virus SARS-CoV-2. Una auténtica perturbación en todos los ámbitos (personal, laboral, económico, social, político, psicológico...). Nuestros modelos políticos y económicos y nuestros recursos en materia de sanidad no saben cómo combatirlo porque no están preparados para ello. Los políticos rivalizan por sus intereses partidistas y personales. A veces pienso que utilizan las ideologías como pantalla para lograr beneficios particulares y no porque crean en esas ideas que predican y dicen defender. La economía por su parte, y sobre todo en el caso de España, es débil porque se asienta en escasos pilares, está poco diversificada. Uno de esos pilares es el turismo. Como la pandemia ha coartado la movilidad de las personas, no ha habido otra alternativa.

El "orden internacional", las administraciones estatales y comunitarias, los partidos políticos se han aferrado al “sálvese quien pueda". En ninguna parte, en ningún ámbito o nivel se observa espíritu de trabajo cooperativo. Las decisiones sanitarias chocan con las prioridades de la gente y con los intereses empresariales y políticos. Los partidos políticos no se ponen de acuerdo. Se tensionan las relaciones entre el ejecutivo y algunas comunidades autónomas...

Por tanto, ¿podemos esperar, en este contexto, que alguna ideología nos saque de esta crisis?. Si un día este virus es combatido aparecerán muchos personajes reivindicando esa autoría. Pero, ¿habrán entendido algo de esta experiencia y de las lagunas que ha dejado al descubierto? ¿Comprenderán algún día que la estupidez no tiene vacuna?. No lo creo. ¿Entenderán alguna vez que el comportamiento de la naturaleza y de otros seres vivos es más inteligente, más colaborativo, más tolerante, más eficaz y menos malvado y egoísta que el comportamiento humano?. Tampoco lo creo. Sólo piensan en populismo, populismo y populismo. Y víctimas propicias no les van a faltar, como bien saben.

El mundo es hoy un sistema cerrado. Las TIC parecen hacerlo más abierto, pero éstas sólo son una creación con ambiciones globalizadoras. De élites que promueven el pensamiento único, que comercian con las informaciones, que saben promover nuevos y más rentables hábitos de consumo.

Se observan dualismos por doquier: de derechas/de izquierdas, españolista/independentista, patriota/antipatriota, español/extranjero, blanco/negro...

A las autoridades educativas, por su parte, este tema no parece que les preocupe lo más mínimo. Tampoco sé de manifestaciones en las que la sociedad civil reivindique la necesidad de una educación más humanística, más amplia en sus horizontes, más útil para la vida, tanto para comprenderla como para saber enfrentarnos a las situaciones. Se habla mucho de autonomía, de espíritu emprendedor, pero culturalmente no se aprecian avances significativos. El emprendimiento se reduce al ámbito empresarial cuando en la vida se puede y se debe ser emprendedor de muchas maneras.

No obstante, la cabeza se puede y se debe amueblar de otro modo, en el respeto y la aceptación de la diferencia, de la diversidad real que es plural y enriquecedora. En la actitud tolerante y sistémica que nos muestra la naturaleza. En el relativismo, el perspectivismo y el pensamiento débil, en la toma de decisiones argumentadas y consensuadas, en el trabajo colaborativo, en la búsqueda de objetivos comunes, en el diálogo. En una forma de pensar que nos ayude a seleccionar, discriminar, relacionar, organizar objetivos y a interactuar. En la educación para la paz, la convivencia pacífica y la igualdad real y efectiva entre hombres y mujeres. En el respeto y la defensa a los derechos humanos.

La mayoría de los ciudadanos votan porque la ley se lo permite por razón de edad, pero sin haber recibido la 
formación sociopolítica y cívica previa que se precisa para ejercer esa acción ciudadana con criterio $y$ con responsabilidad. La política no es ni buena ni mala. Es algo necesario. No es corrupta per se. Quienes se corrompen son algunos políticos. La indiferencia ciudadana y el desdén hacia la acción política no son la solución, sino parte del problema.

Hoy, cuando estoy concluyendo la redacción de este texto, es 12 de Octubre, día de la Hispanidad. En televisión visualizo imágenes de archivo, un despliegue de soldados desfilando, de aviones de combate sobrevolando los cielos de Madrid y, ante la ausencia de este despliegue por la pandemia, a centenares de vehículos ocupando las calles en diferentes ciudades arropados por la bandera de España. También, a políticos reunidos por hipócritas razones de protocolo que no están dispuestos a ceder ni un ápice en sus pretensiones partidistas, que invocan hasta el hastío el nombre de España mientras demuestran, día a día, que los intereses generales de este país no les importan demasiado. Pura demagogia y publicidad, armas políticas eficaces que adormecen fatalmente las conciencias de la estupidez más grosera.

Sin duda, reivindican su identidad de pertenencia a determinados símbolos (de los que se algunos se han apropiado, porque sí) y a su ideología, mostrando públicamente a las claras cuál es su mobiliario mental. Quizás también, recordando a una parte de esa hispanidad quién es España, quién fue, cuánto le deben y su lugar en la jerarquía.

Me gustaría que, un día, la hispanidad se celebrase de otro modo. Con actos culturales abiertos que reflejen la rica diversidad cultural de ese conglomerado llamado hispanidad; de una España comprometida con la investigación y la diversidad cultural; con mesas redondas en las que se hable abiertamente de este tema y que favorezcan la oportunidad de escuchar diversas opiniones y puntos de vista; de los avances en la cooperación internacional; de los derechos de los pueblos indígenas a conservar, al menos, parte de su identidad; de las nefastas consecuencias de los colonialismos e imperialismos; de las desigualdades sociales y de los graves problemas que sufren muchos países hispanos. En fin, me gustaría que el tema de celebración fuese la hispanidad como tal, sin más decoraciones superfluas. Y, si los inspirados organizadores creen no tener nada que celebrar al respecto, que supriman la celebración. Sobra hipocresía por los cuatro costados.

\section{REFERENCIAS}

[1] Althusser, L. (1968) La revolución teórica de Marx. México. Siglo XXI

[2] Angyal, A. (1941) Foundations for a Science of Personality. Harvard University Press

[3] Atlan, H. (1979) Entre le cristal et la fumée. Essai sur l'orgnisation du vivant. París. Seuil

[4] Bertalanffy, L. von (1980) Teoría general de los sistemas. Madrid. FCE

[5] García Valdés, E. (2000) Instituciones suicidas. Estudios sobre ética y politica. México. Paidós-UNAM

[6] García Velarde, M. (1978). Estructuras disipativas y evolución. Boletín Informativo de la Fundación Juan March 69 (marzo 1978); 3-18
[7] Glansdorff, P. y Prigogine, I. (1971) Thermodynamic Theory of Structure. Stability and Fluctuations. New York. Wiley Interscience

[8] Gómez García, P. [Coord.] (2000) Las ilusiones de la identidad. Madrid. Cátedra.

[9] Groot, S.R. (1968). Termodinámica de los procesos irreversibles. Madrid. Alhambra.

[10] Haken, H. y Wunderlin, A. (1990) El caos determinista. Mundo Cientifico 108; 1210-1217

[11] Heisenberg, W. (1976) La imagen de la naturaleza en la fisica actual. Barcelona. Ariel

[12] Lavenda, B.H. (1985). El movimiento browniano. Investigación y Ciencia 103; 36-45

[13] Lurié, D. y Wagensberg, J. (1979) Termodinámica de la evolución biológica. Investigación y Ciencia 30; 82-93

[14] Marina, J.A. y Válgoma, M. de la (2001) La lucha por la dignidad. Barcelona. Anagrama

[15] Marx, K, y Engels, F. (1970) La ideología alemana. Barcelona. Grijalbo.

[16] Morin, E. (1978) El paradigma perdido. Barcelona. Kairós

[17] Morin, E. (1981) El Método I: la naturaleza de la naturaleza. Madrid. Cátedra

[18] Morin, E. (1988) El Método III: el conocimiento del conocimiento. Madrid. Cátedra

[19] Nicolis, G. y Prigogine, I. (1977) Self-Organization in NonEquilibrium Systems. New York. Wiley-Interscience

[20] Nietzsche, F. (1985) Más allá del bien y del mal. Sección Quinta, $\S 188$. Madrid. Alianza

[21] Nietzsche, F. (1970) Obras completas, IV. La voluntad de poder, $§ 1$. Buenos Aires. Prestigio

[22] Nietzsche, F. (1984) Crepúsculo de los ídolos. La razón en la filosofía, $\S 6$. Madrid. Alianza

[23] Nietzsche, F. (1990) Así habló Zarathustra. Primera Parte: de la virtud que hace regalos, 2. Madrid. Alianza

[24] Nietzsche, F. (1986) La genealogía de la moral. Tratado Primero, §9 ss. Madrid. Alianza

[25] Popper, K.R. (1977) Búsqueda sin término. Una autobiografía intelectual. Madrid. Tecnos

[26] Popper, K.R. (1973) La miseria del historicismo. Madrid. Alianza.

[27] Popper, K.R. (1957) La sociedad abierta y sus enemigos. Buenos Aires. Paidós.

[28] Prigogine, I. (1976) La termodinámica de la vida. Biología molecular (selecciones de "La Recherche"). Madrid. Blume; 199-224

[29] Prigogine, I. y Stengers, I. (1983) La nueva alianza. Metamorfosis de la ciencia. Madrid. Alianza

[30] Prigogine, I. (1983) ¿Tan solo una ilusión. Una exploración del caos al orden. Barcelona. Tusquets

[31] Shannon, C.E. y Wiever, W. (1949) The Mathematical Theory of Communication. University of Illinois Press

[32] Sardón Martín, J.L. (1997) Lo humano y la complejidad. Paideía 44; $441-452$

[33] Sardón Martín, J.L. (1990). El concepto de "physis" en Edgar Morin. Esbozo de una metafisica de la complejidad (Tesis doctoral). Recuperado de:

https://summa.upsa.es/viewer.vm?id=8078\&view=main\&lang=es\&search= EL+CONCEPTO+DE+PHYSIS+EN+EDGAR+MORIN

[34] Trefill, J.S. (1988) De los átomos a los quarks. Barcelona Salvat

[35] Vattimo, G. (1995) Más allá de la interpretación. Barcelona. Paidós/ICE-UAB 
[36] Vattimo, G. y Rovatti, P.A. (Eds.) (1995) El pensamiento débil. Dialéctica, diferencia y pensamiento débil. Madrid. Cátedra

[37] Vattimo, G. (1997) El fin de la modernidad. Nihilismo y hermenéutica en la cultura postmoderna. Barcelona. Gedisa
[38] Wagensberg, J. (1985) Ideas sobre la complejidad del mundo. Barcelona. 